\title{
Capacitance tuning of nanoscale split-ring resonators
}

\author{
Jeppesen, Claus; Mortensen, Asger; Kristensen, Anders
}

Published in:

Applied Physics Letters

Link to article, DOI:

10.1063/1.3263191

Publication date:

2009

Document Version

Publisher's PDF, also known as Version of record

Link back to DTU Orbit

Citation (APA):

Jeppesen, C., Mortensen, A., \& Kristensen, A. (2009). Capacitance tuning of nanoscale split-ring resonators. Applied Physics Letters, 95(19), 193108. https://doi.org/10.1063/1.3263191

\section{General rights}

Copyright and moral rights for the publications made accessible in the public portal are retained by the authors and/or other copyright owners and it is a condition of accessing publications that users recognise and abide by the legal requirements associated with these rights.

- Users may download and print one copy of any publication from the public portal for the purpose of private study or research.

- You may not further distribute the material or use it for any profit-making activity or commercial gain

- You may freely distribute the URL identifying the publication in the public portal

If you believe that this document breaches copyright please contact us providing details, and we will remove access to the work immediately and investigate your claim. 


\title{
Capacitance tuning of nanoscale split-ring resonators
}

\author{
Claus Jeppesen, ${ }^{1}$ Niels Asger Mortensen, ${ }^{2}$ and Anders Kristensen ${ }^{1, a)}$ \\ ${ }^{1}$ Department of Micro and Nanotechnology, Technical University of Denmark, DTU Nanotech, \\ Building 345 East, DK-2800 Kongens Lyngby, Denmark \\ ${ }^{2}$ Department of Photonics Engineering, Technical University of Denmark, DTU Fotonik, Building 345 West, \\ DK-2800 Kongens Lyngby, Denmark
}

(Received 23 September 2009; accepted 22 October 2009; published online 12 November 2009)

\begin{abstract}
We investigate the capacitance tuning of nanoscale split-ring resonators. Based on a simple inductor-capacitor circuit model, we derive an expression, where the inductance is proportional to the area while the capacitance reflects the aspect ratio of the slit. The resonance frequency may thus be tuned by the slit aspect ratio leaving the area, the lattice constant $\Lambda$, and nearest-neighbor coupling in periodic structures invariant. Experimental data follow the predictions of the simple LC-model. (C) 2009 American Institute of Physics. [doi:10.1063/1.3263191]
\end{abstract}

Metamaterials are artificially structured electromagnetic materials with exceptional optical properties inherited from the structure of the subwavelength, mesoscopic unit-cell. By carefully designing the unit-cell, materials can be facilitated with a negative effective index supporting negative refraction of incident waves. ${ }^{1}$ The realization of negative-index media combines structures supporting a negative permittivity $\epsilon_{\text {eff }}$ as well as a negative permeability $\mu_{\text {eff }}$. While the plasmonic response of metals already supports the former at optical frequencies, there is a call for geometries also supporting an artificial negative magnetic response. Cut-wires, ${ }^{2}$ "fish-net" structures, ${ }^{3}$ and particularly different types of splitring resonator geometries ${ }^{4-6}$ are central in this context.

Since the seminal work by Pendry et al., ${ }^{7}$ artificial magnetism has been demonstrated at yet higher frequencies. ${ }^{8}$ Recently, split-ring resonators (SRR) have been realized at terahertz frequencies, ${ }^{4,9}$ near-infrared, and visible frequencies. ${ }^{6} 10$ Scaling properties and coupling effects have been subject to numerous theoretical, numerical, and experimental studies. ${ }^{11-16}$

The strong analogy with inductor-capacitor $(L C)$ circuits has motivated substantial efforts in establishing simple circuit models, allowing for an estimate of the resonance frequency

$$
\omega_{0} \simeq 1 / \sqrt{L C},
$$

in terms of geometrical parameters of the SRR structure, see, e.g., Refs. 14 and 16 and references therein. In particular, a linear scaling of the structure causes a simple scaling of the resonance frequency [Eq. (1)], which is inversely proportional to the scale factor. ${ }^{17}$ The concept of scaling applies as long as the metal can be perceived as an ideal metal. Deviations of linear scaling have been observed at optical frequencies. ${ }^{10}$ At lower frequencies the kinetic inductance of the electrons may be neglected and the artificial magnetic response has a purely geometrical origin. ${ }^{18}$ The capacitive response of the SRRs has also been investigated by applying a voltage across the SRRs. ${ }^{19,20}$

In this letter we consider single-slit SRRs and emphasize how the inductance $L$ mainly probes the area $\ell \times \ell$ of the

\footnotetext{
${ }^{\text {a) }}$ Author to whom correspondence should be addressed. Electronic mail: anders@mailaps.org.
}

SRR, while the capacitance $C$ relates to the slit dimension. Obviously, the latter property allows tuning of the frequency, while leaving the area, the lattice constant $\Lambda$, and nearestneighbor coupling in periodic structures invariant.

We apply a simple model of the scaling for the resonance frequency with the slit aspect-ratio $d / w$. Predictions are confirmed by measurements on a large range of SRR samples fabricated by electron-beam lithography (EBL).

In the simplest approach, the SRR geometry in Fig. 1 resembles a plate capacitor with capacitance $C=\varepsilon_{0} w h / d$, where $h$ is the metal-film thickness, $d$ is the slit width, and $w$ is the slit length.

Inductance wise, the SRR geometry mimics a singleloop coil with inductance $L=\mu_{0}(1 / h)^{2}(\ell \times \ell) h$, where $\ell \times \ell$ is the area of the coil. This yields a resonance frequency ${ }^{14}$

$$
\omega_{0}=\frac{c}{\ell} \sqrt{\frac{d}{w}}
$$

where $c=1 / \sqrt{\epsilon_{0} \mu_{0}}$.

To assess this simple model we have prepared eight samples with arrays of SRR, see Fig. 2, each covering an area of $2 \mathrm{~mm} \times 2 \mathrm{~mm}$. The transmission is measured using a $1 \mathrm{~mm}$ diameter laser spot, thus effectively probing an ensemble of $10^{8}-10^{9}$ SRRs.

In fabrication, a $100 \mathrm{~nm}$ thick layer of EBL resist, ZEP520A (3.6\%, Zeon Corp., Tokyo, Japan) is spincoated onto a $1 \mathrm{~mm}$ fused silica substrate. A $15 \mathrm{~nm}$ aluminum layer is thermally deposited on top of the ZEP layer to prevent charge accumulation during EBL. The proximity corrected EBL exposure is performed with a $100 \mathrm{kV}$ JEOL JBX-

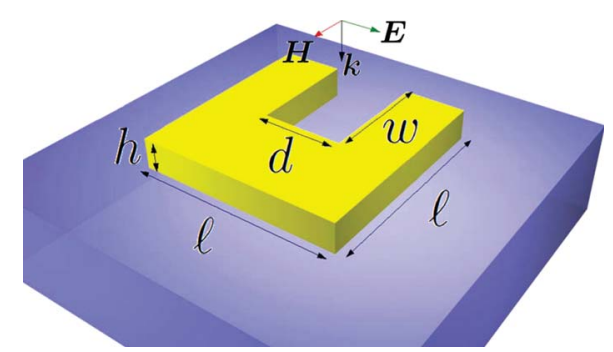

FIG. 1. (Color online) Schematic drawing of the SRR design, indicating central geometrical parameters as well as the polarization configuration of the excitation. 


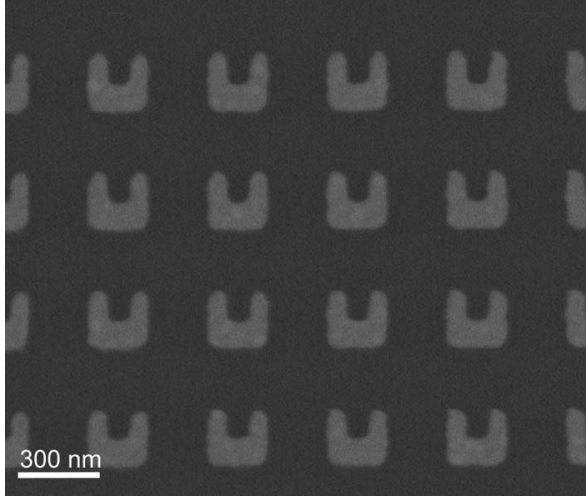

FIG. 2. Micrograph of a SRR array with pitch $\Lambda=440 \mathrm{~nm}$. The fabricated samples have $\ell=200 \mathrm{~nm}, w=90-110 \mathrm{~nm}, d=80 \mathrm{~nm}$, and $h=30 \mathrm{~nm}$.

9300FS EBL tool $\left(200 \mu \mathrm{C} / \mathrm{cm}^{2}\right.$ dose, $2 \mathrm{nA}$ current, and 6 $\mathrm{nm}$ spotsize). The aluminum layer is then removed in MF322 (Rohm and Haas, Coventry, U.K.) and the positive ZEP resist is developed in ZED-N50 (Zeon Corp.) developer. A brief $\mathrm{O}_{2}$ plasma descum process is applied to remove residual resist before $5 \mathrm{~nm} \mathrm{Ti/30} \mathrm{nm} \mathrm{Au}$ is deposited by electron beam deposition. The final lift-off is performed by using Remover 1165 (Rohm and Haas) in an ultrasound bath.

Figure 3 shows normal-incidence transmittance spectra for four samples with the polarization given in Fig. 1. The spectra show a resonance shift toward shorter wavelengths, hence larger frequencies $\left(\lambda_{0}=2 \pi c / \omega_{0}\right)$ as a function of as-

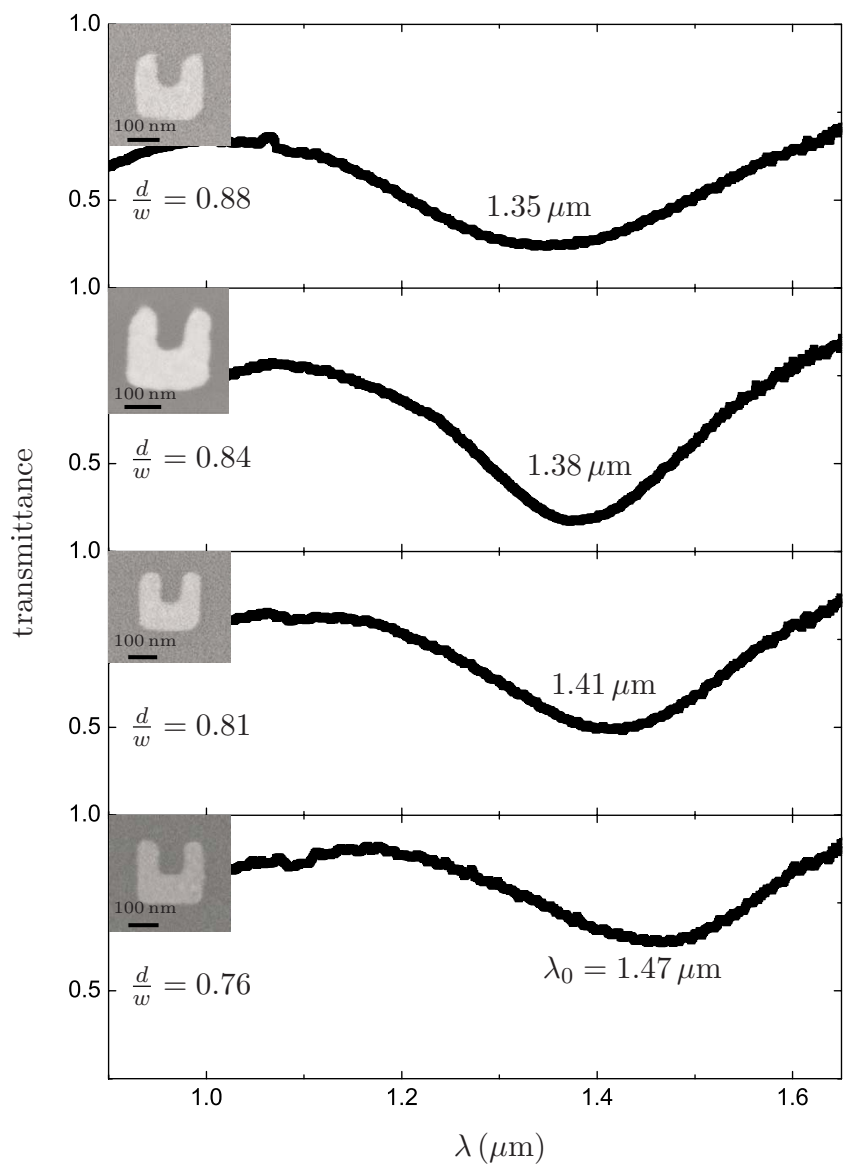

FIG. 3. (Color online) Measured normal incidence transmittance spectra for four samples with $\ell=200 \mathrm{~nm}$ and $d=80 \mathrm{~nm}$. The resonance wavelength $\lambda_{0}$, the ratio $d / w$, and a micrograph for each sample is given.

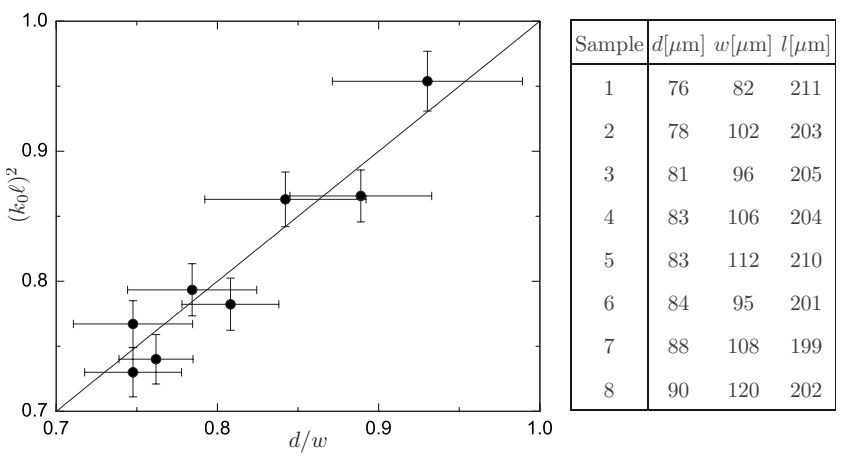

FIG. 4. Plot of $\left(k_{0} \ell\right)^{2}$ vs $d / w$. The corresponding SRR dimensions are listed in the table. The solid line shows Eq. (3) without any free parameters. The $\mathrm{x}$-error bars represent the standard deviation (SD) of ten individual measurements of $w$ and $d$ added together. The y-error bars is the $1 \mathrm{~nm}$ spectral resolution of the Ando AQ-6315E optical spectrum analyzer added to the SD of ten measurements of the length $\ell$.

pect ratio $d / w$. This is in good agreement with the predictions of Eq. (2).

In Fig. 4 we compare the measurements to our model. For a clearer confirmation of the scaling with the slit-aspect ratio $d / w$, we rewrite Eq. (2) as

$$
\left(k_{0} \ell\right)^{2}=\frac{d}{w}
$$

using $\lambda_{0}=2 \pi / k_{0}$. Thus giving a linear relationship between the free-space wave number, $k_{0}$, and the slit aspect ration, $d / w$. Clearly, the experimental data confirms this scaling. Within the measurement uncertainties we even find quantitative agreement with our simple model.

In conclusion, we have fabricated metamaterials consisting of periodic arrays of subwavelength, nanoscale SRR. The structures offer an artificial magnetic response around 1400 $\mathrm{nm}$ wavelength. Our key observation is that the capacitance of SRR may be tuned by simple geometrical means without affecting the inductance significantly. This allows for frequency scaling without changing the over-all scale of the SRR and/or the lattice constant of the periodic lattice of SRRs.

The authors thank R. Malureanu for technical assistance. This work was financially supported by The Danish Research Council for Technology and Production Sciences (Grant No. 274-07-0057).

${ }^{1}$ J. B. Pendry and D. R. Smith, Phys. Today 57, 37 (2004).

${ }^{2}$ V. M. Shalaev, W. S. Cai, U. K. Chettiar, H. K. Yuan, A. K. Sarychev, V. P. Drachev, and A. V. Kildishev, Opt. Lett. 30, 3356 (2005).

${ }^{3}$ S. Zhang, W. J. Fan, K. J. Malloy, S. R. J. Brueck, N. C. Panoiu, and R. M. Osgood, Opt. Express 13, 4922 (2005).

${ }^{4}$ T. J. Yen, W. J. Padilla, N. Fang, D. C. Vier, D. R. Smith, J. B. Pendry, D. N. Basov, and X. Zhang, Science 303, 1494 (2004).

${ }^{5}$ N. Katsarakis, G. Konstantinidis, A. Kostopoulos, R. S. Penciu, T. F. Gundogdu, M. Kafesaki, E. N. Economou, T. Koschny, and C. M. Soukoulis, Opt. Lett. 30, 1348 (2005).

${ }^{6}$ C. Enkrich, M. Wegener, S. Linden, S. Burger, L. Zschiedrich, F. Schmidt, J. F. Zhou, T. Koschny, and C. M. Soukoulis, Phys. Rev. Lett. 95, 203901 (2005).

${ }^{7}$ J. B. Pendry, A. J. Holden, D. J. Robbins, and W. J. Stewart, IEEE Trans. Microwave Theory Tech. 47, 2075 (1999).

${ }^{8}$ C. M. Soukoulis, S. Linden, and M. Wegener, Science 315, 47 (2007).

${ }^{9}$ S. Linden, C. Enkrich, M. Wegener, J. F. Zhou, T. Koschny, and C. M. Soukoulis, Science 306, 1351 (2004).

${ }^{10}$ M. W. Klein, C. Enkrich, M. Wegener, C. M. Soukoulis, and S. Linden, Opt. Lett. 31, 1259 (2006). 
${ }^{11}$ N. Katsarakis, T. Koschny, M. Kafesaki, E. N. Economou, and C. M. Soukoulis, Appl. Phys. Lett. 84, 2943 (2004).

${ }^{12}$ C. Rockstuhl, F. Lederer, C. Etrich, T. Zentgraf, J. Kuhl, and H. Giessen, Opt. Express 14, 8827 (2006).

${ }^{13}$ H. C. Guo, N. Liu, L. W. Fu, T. P. Meyrath, T. Zentgraf, H. Schweizer, and H. Giessen, Opt. Express 15, 12095 (2007).

${ }^{14}$ H. C. Guo, N. Liu, L. W. Fu, H. Schweizer, S. Kaiser, and H. Giessen, Phys. Status Solidi B 244, 1256 (2007).

${ }^{15}$ M. Decker, S. Linden, and M. Wegener, Opt. Lett. 34, 1579 (2009).

${ }^{16}$ T. D. Corrigan, P. W. Kolb, A. B. Sushkov, H. D. Drew, D. C. Schmadel, and R. J. Phaneuf, Opt. Express 16, 19850 (2008).

${ }^{17}$ S. O'Brien and J. B. Pendry, J. Phys.: Condens. Matter 14, 6383 (2002).

${ }^{18}$ K. Aydin, I. Bulu, K. Guven, M. Kafesaki, C. M. Soukoulis, and E. Ozbay, New J. Phys. 7, 168 (2005).

${ }^{19}$ I. Gil, J. Garcia-Garcia, J. Bonache, F. Martin, M. Sorolla, and R. Marques, Electron. Lett. 40, 1347 (2004).

${ }^{20}$ T. Driscoll, H.-T. Kim, B.-G. Chae, B.-J. Kim, Y.-W. Lee, N. M. Jokerst, S. Palit, D. R. Smith, M. Di Ventra, and D. N. Basov, Science 325, 1518 (2009). 